\title{
EXAMINING THE LATENT PERIOD OF SEPTORIA TRITICI BLOTCH IN A FIELD TRIAL OF WINTER WHEAT
}

\author{
T. ARMOUR, S.L.H. VILJANEN-ROLLINSON, S. CHNG, \\ R.C. BUTLER, P.D. JAMIESON and R.F. ZYSKOWSKI \\ Crop \& Food Research, Private Bag 4704, Christchurch, New Zealand \\ Corresponding author: armourt@crop.cri.nz
}

\begin{abstract}
The wheat cultivar Consort was artificially inoculated with Septoria tritici in an experiment to determine the latent period of the pathogen in New Zealand. Three individual leaf layers (leaf three, leaf two or the flag leaf) were inoculated over three sowing dates to provide a range of different environmental conditions following inoculation. The mean latent period was 21 to 27 days $\left(291-372^{\circ} \mathrm{C}\right.$ days). The length of the latent period increased slightly with delays in sowing date. The implications for producing a simple forecasting system to assist farmers with timing of fungicide applications are discussed.
\end{abstract}

Keywords: latent period, Septoria tritici, winter wheat, modelling, disease control.

\section{INTRODUCTION}

Septoria tritici blotch (STB), caused by Septoria tritici Roberge in Desmaz. (teleomorph Mycosphaerella graminicola (Fückel) J. Schrot.), is a foliar disease of autumn-sown wheat (Triticum aestivum) crops. Rainfall during stem extension assists disease spread into the upper leaves of the canopy (Shaw \& Royle 1986). Yield losses occur when the top two or three leaves, which are important contributors to grain filling, become infected (Shaw \& Royle 1989; Thomas et al. 1989). New Zealand (NZ) growers aim to protect these leaves from STB, typically using three fungicide applications that coincide with the full emergence of final leaf three, the flag leaf (final leaf), and at flowering.

Disease pressure and weather conditions vary from season to season, and three fungicide applications may not always be necessary (Armour et al. 2003). In countries where STB is a major disease, weather-based prediction models have been developed in an effort to curb potential over-application (Thomas et al. 1989; Shtienberg et al. 1990; Verreet 1995; Moreau \& Maraite 1999). Such models assist growers when making decisions about the need to spray based on the risk of disease spread caused by certain weather criteria. Identifying these criteria relies on a good understanding of pathogen epidemiology, particularly the time elapsed between infection and the appearance of disease symptoms on a leaf layer (latent period). Knowing the length of the latent period under different environmental conditions assists in identifying the conditions or events that caused the infection. Furthermore, length of latent period is an important epidemiological factor in the subsequent spread of the pathogen within and beyond the crop (Shaw \& Royle 1993). Weather-based prediction models have the potential to be used by growers in NZ, as long as they are supported by information on pathogen biology in NZ field conditions.

The objective of this study was to determine the latent period for STB under NZ field conditions following artificial inoculation of wheat plants at various stages of development. This information will enable the development of guidelines that assist growers with decisions about fungicide applications when the disease is present in their crops. 


\section{MATERIALS AND METHODS}

\section{Design}

Thirty-six plots of wheat cultivar Consort were sown at the Crop \& Food Research site at Lincoln, Canterbury, in 2003. Plots were $11 \mathrm{~m}$ long by nine rows wide $(15 \mathrm{~cm}$ spacing). The trial was laid out in a row and column design, with a complete replicate in each row of plots.

The treatments consisted of three sowing dates (SD), 29 May 2003 (May), 27 June 2003 (June) and 13 August 2003 (August), and three inoculation timings, replicated four times. The inoculations were applied to individual leaf layers in a plot at the full emergence of leaf three (L3), leaf two (L2) or the flag leaf (FL) (Table 1). This gave nine sets of environments, determined by the varying conditions from each inoculation date.

Each plot received $46 \mathrm{~kg} / \mathrm{ha}$ of urea (46\% nitrogen) on 15 September and 4 November, and $30 \mathrm{~mm}$ of water was applied on five occasions.

\section{TABLE 1: Date when each wheat leaf treatment in each sowing date was inoculated with Septoria tritici.}

\begin{tabular}{lccc}
\hline & May & June & August \\
\hline Leaf 3 & $28 / 10 / 03$ & $07 / 11 / 03$ & $24 / 11 / 03$ \\
Leaf 2 & $05 / 11 / 03$ & $12 / 11 / 03$ & $01 / 12 / 03$ \\
Flag leaf & $12 / 11 / 03$ & $19 / 11 / 03$ & $08 / 12 / 03$ \\
\hline
\end{tabular}

\section{Inoculum preparation and inoculation}

Leaves infected with $S$. tritici were collected in October 2003 from naturally infected wheat plants at Lincoln. Isolation of pycnidia and production of inoculum proceeded using the methods described by Eyal et al. (1987). Spore concentration was adjusted to $1 \times 10^{7}$ spores $/ \mathrm{ml}$ and a drop of surfactant (Tween 20) was added to the inoculum.

Just prior to inoculation, 10 tillers were selected (five tillers from two rows) at each end of the plot and labelled below the last fully emerged leaf. The fully emerged leaves at the southern end of the plot were then inoculated using a Humbrol atomiser, and covered with a moistened plastic bag overnight to ensure germination. Inoculations were made under a cage covered in plastic to prevent the wind from blowing the inoculum into neighbouring plots. Tagged plants at the northern end of each plot were left untreated to allow any natural inoculum that could affect the results of the inoculated plots to be identified.

\section{Assessments and analysis of data}

Visual assessments for pycnidia on the leaf above each tag were made at both ends of the plot, 15-18 days after each inoculation. Leaves were then examined three times each week until disease was observed. Weather data was obtained from a weather station approximately $1 \mathrm{~km}$ from the trial site.

The latent period (LP) was defined as the time interval from inoculation until pycnidia appeared. This was examined in two ways: (i) time to first appearance of pycnidia (FP) in a plot and (ii) time until all the leaves in the plot showed infection (AP). Symptom expression (SE) was defined as the time interval from FP to AP. Measurements were expressed as days or thermal time (base temperature $0^{\circ} \mathrm{C}$ ), and were analysed using analysis of variance (GenStat $6^{\text {th }}$ Edition). Leaves that were missing (due to lost tags), had other diseases or were dead on any assessment date were removed from the analysis before calculation of FP, AP and SE. Missing data were as follows: one L2 from each SD, three L3 from the August SD, and two, six and five FL from the May, June and August SD respectively.

\section{Inoculation and infection}

\section{RESULTS}

Natural infections of STB were not found on any of the tagged, uninoculated leaves. Therefore, no adjustments needed to be made when interpreting the data for the inoculated plants. All inoculated leaves became infected. 


\section{First appearance of pycnidia (FP)}

Pycnidia were first observed 19 days $\left(229^{\circ} \mathrm{C}\right.$ days) following inoculation, in six of the 36 plots. The mean time to FP for all plots was 21.3 days $\left(291^{\circ} \mathrm{C}\right.$ days $)$. Overall, the August SD took longer to reach FP, by one and a half days $(\mathrm{P}<0.05)$, mostly due to the longer FP for the FL and L3 (Table 2). There were no overall differences between leaf layers. There was substantial variation $(\mathrm{P}<0.05)$ between leaf layers and SD when analysed in thermal time. Pycnidia were visible on the $\mathrm{FL}$ of the May SD $34^{\circ} \mathrm{C}$ days earlier than on L2 of the same SD. All leaves in the August SD took at least $30^{\circ} \mathrm{C}$ days longer to reach FP than the May and June SD.

TABLE 2: Mean number of days and thermal time to the first appearance of pycnidia (FP) for three different leaves sown at three sowing dates and inoculated with Septoria tritici. $(\mathrm{LSD}=\mathrm{P}<0.05, \mathrm{df}=24)$

\begin{tabular}{|c|c|c|c|c|c|c|c|c|}
\hline \multirow[b]{2}{*}{ Leaf } & \multicolumn{4}{|c|}{ Days } & \multicolumn{4}{|c|}{ Thermal time $\left({ }^{\circ} \mathrm{C}\right.$ days $)$} \\
\hline & May & June & August & LSD & May & June & August & LSD \\
\hline L3 & 20.5 & 20.8 & 22.5 & & 271.8 & 264.3 & 322.4 & \\
\hline $\mathrm{L} 2$ & 21.7 & 21.0 & 21.5 & & 284.4 & 257.5 & 330.4 & \\
\hline Flag & 20.5 & 20.5 & 23.0 & 2.3 & 249.2 & 273.9 & 365.0 & 30.4 \\
\hline
\end{tabular}

\section{Period of symptom expression (SE)}

The results for SE closely follow those for FP and AP. The number of leaves infected in each plot increased sigmoidally with time. SE ranged from two to nine days, with a mean of 5.2 days $\left(81^{\circ} \mathrm{C}\right.$ days). L3 and FL from the May SD, and L3 from the August SD had the shortest SE period in days (Fig. 1a) and thermal time. There were considerable differences $(\mathrm{P}<0.05)$ in the length of SE between leaf timings for the May and August SD.

\section{Environmental conditions}

Plants in the August SD experienced several days when maximum temperatures equalled or exceeded $30^{\circ} \mathrm{C}$. Nevertheless, mean temperatures following inoculation of each leaf layer and SD were similar to the long-term means. Delays in SD meant that plants in the later sowing dates and subsequent leaf layers had warmer temperatures following inoculation (Fig. 1b).

\section{DISCUSSION}

Knowledge of the LP can be used to identify environmental conditions associated with infection. By modelling the LP in this experiment, it is possible to estimate the time of infection in relation to our observations of symptom expression for this wheat cultivar.

Our mean LP of 21 to 27 days $\left(291-372^{\circ} \mathrm{C}\right.$ days) was slightly longer than that reported by Shaw (1990) of 17 to 21 days at $16.4^{\circ} \mathrm{C}$, and the 14 to 21 days observed by Eyal et al. (1987) and Holloman et al. (1999). Some of the variation could be due to the cultivars used in each study as LP has shown to vary between cultivars (Shaw 1990). As observations were only every third or fourth day, pycnidia may have appeared up to two days earlier than recorded. First observations of FP, at 19 days, could have represented pycnidia appearing around 17 days following an infection event. Temperatures recorded were close to seasonal average temperatures, so we would expect the LP for wheat cultivar Consort to be similar in years when seasons are typical. The presence of secondary infection can be ruled out as all leaves developed pycnidia within one LP of the first observation of pycnidia. 
a)

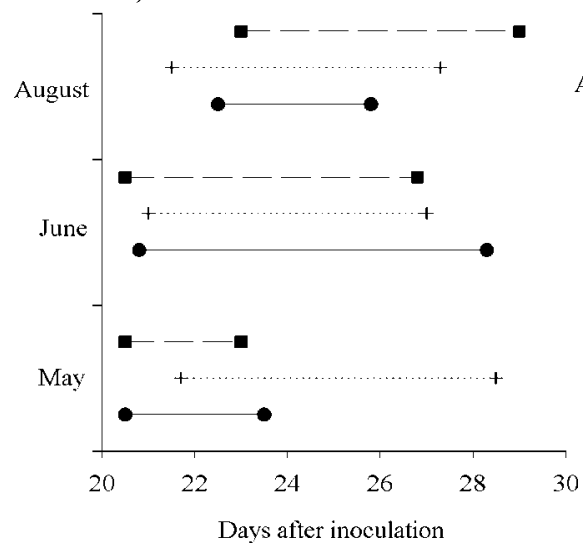

b)

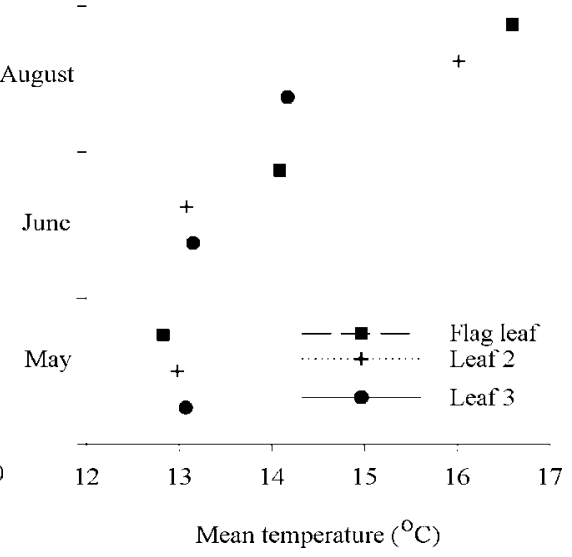

FIGURE 1. (a) The commencement and duration (days) of symptom expression, and (b) mean temperature from inoculation to the end of the symptom expression period, for leaves inoculated with Septoria tritici at three different stages of crop development over three sowing dates.

The LP in thermal time proved to be more variable than in days, for reasons that are unclear. In studies where a range of temperatures were used in growth cabinets (Shaw 1990; Chungu et al. 2001), very definite temperature effects were found. Those studies report a decrease in the length of the LP associated with increasing temperature. In contrast, our study was conducted under a narrow range of temperatures, meaning that any temperature effects may have been masked by other influences. Such influences could be attributed to the presence of leaf rust (Puccinia recondita f.sp. tritici) and temperatures exceeding $30^{\circ} \mathrm{C}$, which only affected leaves of plants in the August SD.

\section{CONCLUSIONS}

Calculation of LP will enable us to identify the weather conditions that coincide with infection and allow us to predict disease risk in future seasons under normal conditions for this wheat cultivar. Combined with crop phenology, cultivar susceptibility and chemical information, fungicide guidelines could be developed that assist growers to make decisions about spray applications when the disease is present in their crops. Further research into the effect of cultivar susceptibility on LP, the presence and quantity of inoculum in the lower canopy, crop phenology and chemical efficacy, as well as the impact of high temperatures and other diseases, would be required before releasing such guidelines to growers.

\section{ACKNOWLEDGEMENTS}

Funding for this research was provided by the New Zealand Foundation for Research, Science and Technology and the Foundation for Arable Research. Cathy Munro sowed and managed the trial and Heike De Silva assisted with inoculations and data collection.

\section{REFERENCES}

Armour, T.; Viljanen-Rollinson, S. L. H.; Chng, S. F.; Butler, R. C.; Cromey, M. G.; Jamieson, P. D.; Zyskowski, R. F. 2003: Influence of crop growth and weather conditions on speckled leaf blotch in winter wheat. N.Z. Plant Prot. 56: 246-250. 
Chungu, C.; Gilbert, J.; Townley-Smith, F. 2001: Septoria tritici blotch development as affected by temperature, duration of leaf wetness, inoculum concentration and host. Plant Disease 84: 430-435.

Eyal, Z.; Scharen, A.L.; Prescott, J.M.; Ginkel, M.V. 1987: The Septoria diseases of wheat: concepts and methods of disease management. CIMMYT, Mexico City, Mexico. $52 \mathrm{p}$.

Holloman, D.W.; Fraaije, B.; Rohel, E.; Butters, J.; Kendall, S. 1999: Detection and Diagnosis of Septoria Diseases: The Problem in Practise. In: Lucas, J.A.; Bowyer, P.; Anderson, H.M. ed. Septoria on cereals: a study of pathosystems. CABI Publishing, Oxon, England. Pp. 273-285.

Moreau, J.-M.; Maraite, H. 1999: Integration of knowledge on wheat phenology and Septoria tritici epidemiology into a disease risk simulation model validated in Belgium. Aspects Appl. Biol. 55: 1-6.

Shaw, M.W. 1990: Effects of temperature, leaf wetness and cultivar on the latent period of Mycosphaerella graminicola on winter wheat. Plant Path. 39: 255-268.

Shaw, M.W.; Royle, D.J. 1986: Saving Septoria fungicide sprays: the use of disease forecasts. British Crop Protection Conference - Pests and Diseases. Pp. 1193- 200.

Shaw, M.W.; Royle, D.J. 1989: Airborne inoculum as a major source of Septoria tritici (Mycosphaerella graminicola) infections in winter wheat crops in the UK. Plant Path. 38: 35-43.

Shaw, M.W.; Royle, D.J. 1993: Factors determining the severity of epidemics of Mycosphaerella graminicola (Septoria tritici) on winter wheat in the UK. Plant Path. 42: 882-899.

Shtienberg, D. 1990: Effect of foliar diseases of wheat on the physiological processes affecting yield under semi-arid conditions. Plant Path. 40: 533-541.

Thomas, M.R.; Cook, R.J.; King, J.E. 1989: Factors affecting development of Septoria tritici in winter wheat and its effect on yield. Plant Path. 38: 246-257.

Verreet, J.A. 1995: Principles of integrated pest management: the IPM wheat model. Pflanzenschutz Nachrichten Bayer (English ed) 48.307 p. 